\title{
Questions and responses in Yélî Dnye, the Papuan language of Rossel Island
}

\author{
Stephen C. Levinson ${ }^{\mathrm{a}, \mathrm{b}, *}$ \\ ${ }^{a}$ Max Planck Institute for Psycholinguistics, P.O. Box 310, 6500 AH Nijmegen, The Netherlands \\ ${ }^{\mathrm{b}}$ Radboud University, P.O. Box 9102, 6500 HC Nijmegen, The Netherlands
}

\section{A R T I C L E I N F O}

\section{Article history:}

Received 4 February 2010

Accepted 1 April 2010

\section{Keywords:}

Papuan languages

Questions

Visual signals

Interaction

Prosody

Wh-movement

\begin{abstract}
A B S T R A C T
A corpus of 350 naturally-occurring questions in videotaped interaction shows that questions and their responses in Yélî Dnye (the Papuan language of Rossel Island) both conform to clear universal expectations but also have a number of language-specific peculiarities. They conform in that polar and wh-questions are unrelated in form, whquestions have the usual sort of special forms, and responses show the same priorities as in other languages (for fast cooperative, adequate answers). But, less expected perhaps, Yélî Dnye polar questions (excepting tags) are unmarked in both morphosyntax and prosody, and the responses include conventional facial expressions, conforming to the propositional response system type (so that assent to 'He didn't come?' means 'no, he didn't'). These visual signals are facilitated by high levels of mutual gaze making rapid early responses possible. Tags can occur with non-interrogative illocutionary forces, and could be held to perform speech acts of their own. Wh-questions utilize about a dozen wh-forms, which are only optionally fronted, and there are some interesting specializations of forms (e.g. 'who' for any named entities other than places). Most questions of all types are genuinely information seeking, with $27 \%$ (mostly tags) seeking confirmation, $19 \%$ requesting repair.
\end{abstract}

(c) 2010 Elsevier B.V. All rights reserved.

\section{Background: the language and community ${ }^{1}$}

Yélî Dnye is an isolate, with no clear relation to any other existing language ('Papuan' is a residual category used in Melanesian linguistics). It is spoken on Rossel Island, about $450 \mathrm{~km}$ offshore from Papua New Guinea, by just over 4000 people. Rossel Island has a language and culture distinctively its own. The island has no regular transport, shops, power or other utilities, but rich fisheries bring others to its shores, and it has had missionaries for fifty years, bringing education in English, the lingua franca of the province. There is a sketch grammar of the language by Henderson (1995) and a full scale grammar in preparation (Levinson, forthcoming), along with a number of specialist papers, by the current author (see, e.g. Levinson, 2005, 2007). The language has 90 phonemes, some complex enough to require IPA tetragraphs, which are represented in the practical orthography used here by up to three characters: for example, $d n$ and $n d$ are unrelated phonemes (the first is a post-alveolar stop with a devoiced nasal release, the second a prenasalized postalveolar stop). The language is a case-marking language, thoroughly ergative in character, but it also has elaborate cross-indexing on the verb of subject and object, in complex portmanteau clitics which also code for tense/aspect/person/number and many other factors like

\footnotetext{
* Correspondence address: Max Planck Institute for Psycholinguistics, P.O. Box 310, 6500 AH Nijmegen, The Netherlands. E-mail address: stephen.levinson@mpi.nl.

1 My thanks to my fellow editors and to two anonymous referees for very helpful suggestions, shamelessly incorporated.
} 
negation and counterfactuality. Verbs mostly supplete, and there are many irregularities that make the language extremely hard for second-language learners. Especially relevant for this paper are the following grammatical facts. The language has, in principle, free phrase order, but in practice there is a strong tendency to SOV ordering, and it has postpositions and other features consistent with that ordering. The internal structure of the major phrases, however, is fairly rigid; there is no VP constituent, although there is verb complex consisting of tense/aspect/person clitics which flank the verb.

Another background fact of some relevance is the special nature of Rossel interaction style. Extensive video of social interaction shows that visual displays on the face (eye-pointing, conventional signals such as eye-brow flashes and extended blinks) play an important role in the conduct of interaction. More detail can be found in Levinson (2007) and Rossano et al. (2009).

The following description of patterns in Rossel island questioning is based on grammatical work in Levinson (forthcoming) and a detailed study of questions as used in informal conversation, first reported here. This study employed about 90 min of videotape selected from five different situations, all informal conversations, with changing personnel (people coming and going), thus involving altogether 24 speakers. About 350 questions (195 polar, the remainder nearly all content questions) and their responses were coded in ELAN (video annotating software) for the properties described in the introduction to this special issue.

\section{The grammar of questions}

There is no general interrogative marker, either morphosyntactic or prosodic, common to questions of different types. Both declaratives and polar interrogatives are structurally unmarked, while content questions are marked only by Whwords of different kinds. Other sentence types which contrast are imperatives in three persons (i.e. expressing obligations of addressees, speakers or third parties), and minor sentence types coding wishes ("if only ..."), suggestions and the like.

The details of the interrogative structures now follow.

\subsection{Polar questions}

Polar questions are identical to declaratives in form (as they are in perhaps $16 \%$ of languages, see Dryer, 2008$)^{2}$ Declaratives are the unmarked sentence type (i.e. take no special illocutionary force markers), and consist of three main types of clauses: transitive, typically AOV in phrase order, intransitives (typically SV in phrase order), and verbless equatives (typically with predicating adjective or NP in final position). In practice, many polar questions are elliptical, since all argument NPs can be dropped, and may consist of only a few words.

So polar questions are in declarative format, but are they distinctively marked prosodically? No clear ways of indicating interrogativity either prosodically or kinesically have yet been found. Questions and their answers often seem to closely match in prosody, as the example in Fig. 1 of a question and its answer with matching intonation illustrates. A's question has falling intonation, as does the answer which repeats most of the words but with emphasis on yi tpile, "those things" which was coded only by the final agreement enclitic dé 'them' in A's question. The similarity between the intonation in question and answer is striking, and many similar examples can be found (see also Selting, 1994). The lack of either formal or intonational marks of interrogativity is typologically highly unusual (only 1 of 842 languages are reportedly of this type in Dryer, 2008).

A full scale investigation of intonation in Yélî Dnye questions is underway, but so far it looks like polar questions are primarily detected by virtue of the informational mismatch between speaker and addressee. Since the addressee will by default be assumed to have greater control of information in his private domain, if the speaker makes a statement about, e.g. the addressee's hunger, his children or his future plans, then if it can be heard as a question, it will be treated as such.

For those raised on the standard assumption of rising intonation as a universal marker of questions, it may be sobering to find that, actually, corpora of spoken English show that at least 50\% of yes/no questions are in declarative form, and the great majority of these display falling intonation (Stenström, 1984 found that 75\% of English questions in declarative form had falling intonation; see also Geluykens, 1988). Thus in most cases, English participants rely on pragmatic inference to detect a polar question (see also Stivers, this issue). If the pragmatic inference works well enough to detect more than half the English polar questions, it is powerful enough to be the main questioning strategy in a language, as it is Yélî Dnye (see also Italian, this issue).

The main way to detect a yes/no question seems to be by ascertaining that the speaker is unlikely to know the information at issue, and has reason to think that the addressee may know it. Presumed epistemic mismatch thus acts as the clue to polar questionhood. This principle was described by Labov and Fanshel (1977) as the "B-event" implicit question type (where B is the addressee who is presumed by speaker A to know about the event or state in question). As we will see in section 4 below, this presumption about who is likely to know what can also play an important role in detecting to whom a question is addressed.

Polar questions are well known to vary cross-linguistically in their canonical answering systems (see, e.g. Jones, 1999; Chisholm et al., 1984; Ultan, 1978), and Yélî has a distinctive pattern. Example $<1>$ (partially constructed) shows the canonical form of a polar question-answer sequence. Note that A's question has exactly the same format as a statement

\footnotetext{
${ }^{2}$ Given the lack of a polar interrogative form, I refer to declaratives that function as yes-no questions as polar questions
} 
(A) "ee, they would go and check them again?"

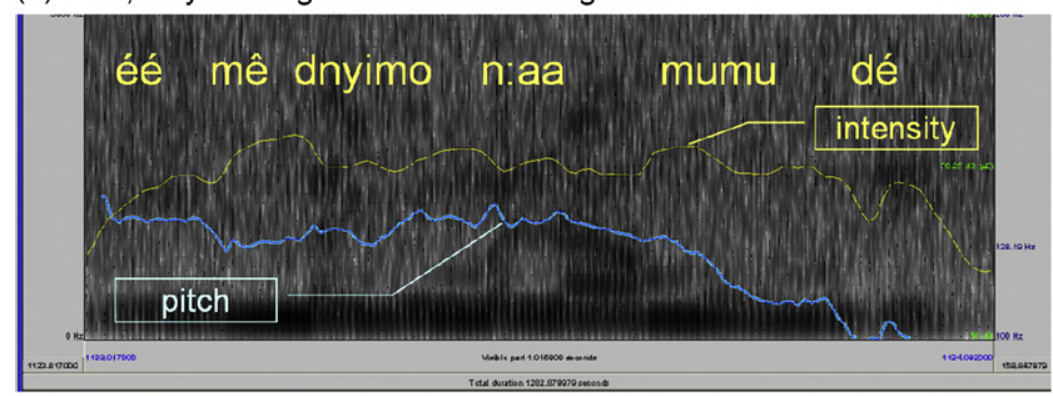

(B) "those things they would go and check them again"

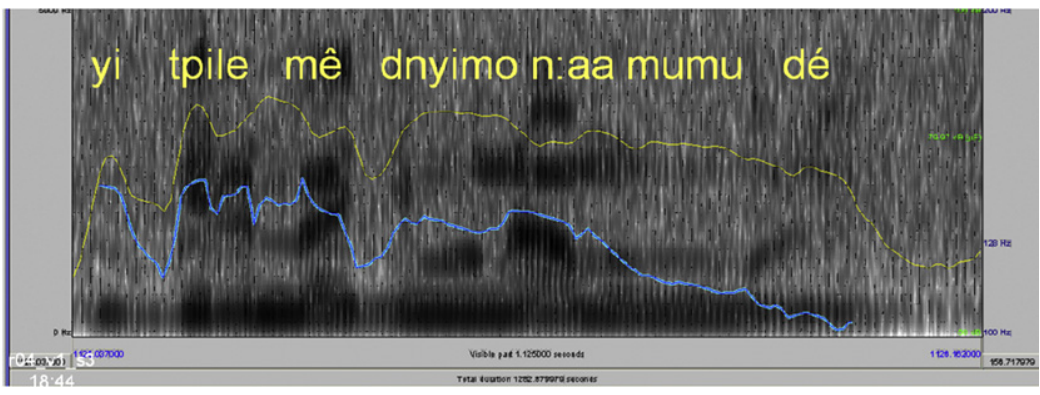

Fig. 1. A declarative question with falling intonation and matching response.

(incidentally, there is no overt subject noun phrase in the question - all NPs in this language are dropped if their reference is clear in context and from the verbal cross-referencing). The positive response is likely to be complete just with an agreement token indicating 'yes', while the negative response is more likely to include both a negative element and a repetition (see section 4 below).

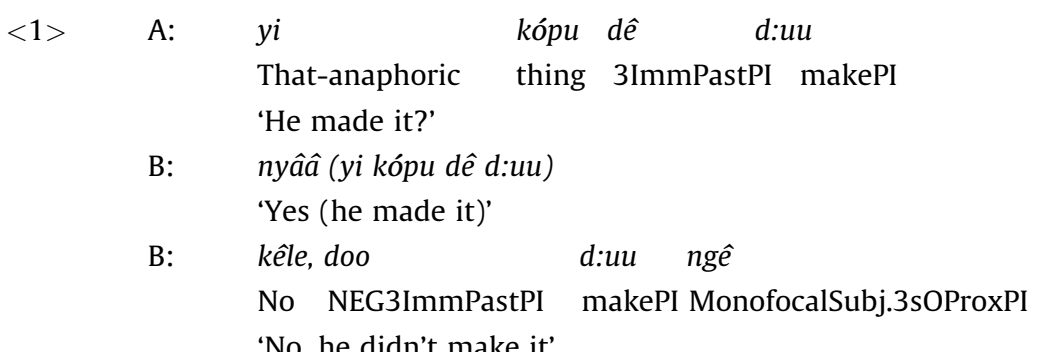

So far, this looks English-like. But the answering system for polar questions is of the truth-affirming type, unlike English, but like Japanese. That is, if what the questioner says can be thought of as a true statement, the answer is 'yes', if false it is 'no'. Thus if the questioner issues a negative question in statement form, nyâa 'yes' indicates that the negative state of affairs holds (i.e. the recipient agrees with the negative proposition expressed by the questioner):

$<2>$ A: doo $u$ ntââ, daa nye lê

NEG_Equative 3POSS sufficient NEG 2sFUTPI go

'It's not enough, you're not going? (the sea is too rough)'

B: $\quad$ nyââ

'Yes (I am not going)'

If this is hard to grasp, think of it like this: the speaker asks: "Do you agree to the proposition that you are not going", to which the natural answer is "Yes, I agree". Such a system again underlies the close relation between assertion and polar question.

Returning to the answering system, a second basic fact about Yélî Dnye answers is that both positive and negative answers to polar questions are often delivered kinesically. A "yes" answer can be given by an eye-brow flash (rapid raising of both eye-brows by contraction of the frontalis muscle), and also by a purposeful blink of the eyes. Stills of these signals are shown in Fig. 2 below. Note that the deployment of these signals exactly follows the logic of the answering system: after a negative question ("You are not going"), an eye-brow flash means "Correct, I am not going". 

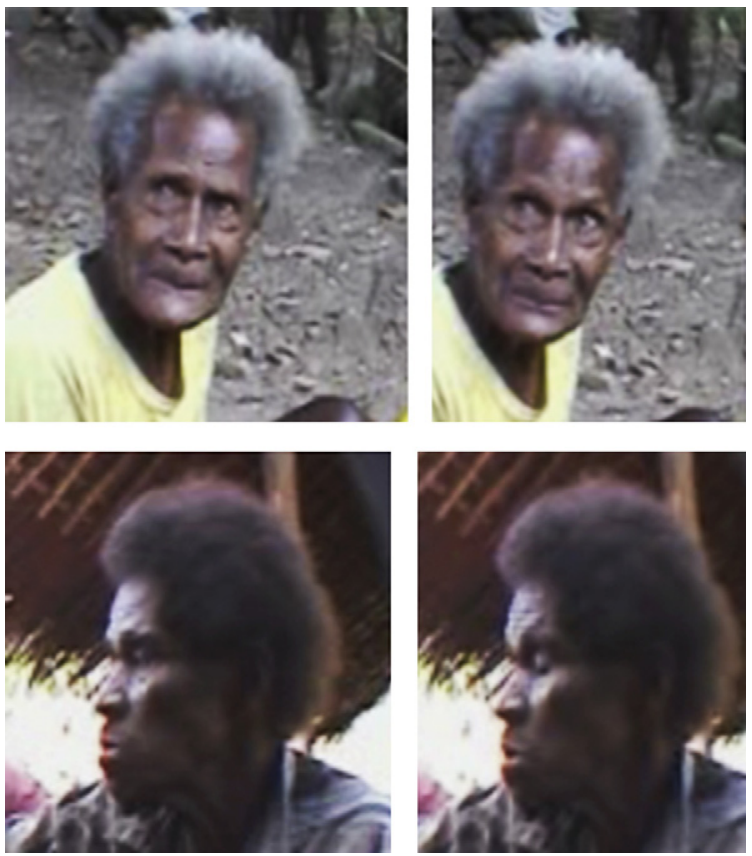

Fig. 2. Eye-brow flash (top panel) and intentional blink (bottom panel).

Table 1

Expressions that function as tags.

\begin{tabular}{|c|c|c|c|}
\hline Expression & Gloss & Source or literal meaning & Uses \\
\hline apii & 'right?' & 2s imperative form of a quotation particle, 'You say X! & Seeks agreement to, e.g. an arrangement or a fact \\
\hline cha w:ee & 'See?' & 'Did you understand?' & Asks for receipt token after, e.g. a statement \\
\hline (kî) chi ny:oo & ‘OK?’ & 'Did you hear (it)?' & Seeks acknowledgement, e.g. of a truth \\
\hline lama & 'You know?' & 'your knowledge’ & Asks for response, e.g. after a statement \\
\hline kî chi m:uu & 'See?' & 'You were seeing it?' & Asks for response after, e.g. a statement \\
\hline éé? & 'Eh?’ & particle used as continuer, but here with high pitch onset & demands response \\
\hline$k w i$ & 'Say!' & 2nd person singular imperative of a quotation particle & asks for confirmation, e.g. from expert \\
\hline
\end{tabular}

Since there is no formal difference between polar questions and statements, and prosody appears to do little to distinguish the two, there is scope for a number of particles or expressions that can act as tags, or demands for a response. ${ }^{3} \mathrm{~A}$ third of all polar questions (34\% of 196 polar questions) are followed by one of these tag expressions, often though after a pause as a follow up, requesting response. The expressions always follow the clause, ${ }^{4}$ and have rather different sources, as made clear in Table 1: some are conventionalized minimal clauses with inflected main verbs, literally meaning, e.g. 'do you understand?', 'do you see?', while others are derived from a large inventory of inflectable quotation particles, literally meaning, e.g. 'you say it!'. One form lama is derived from the noun meaning 'knowledge' with here a silent nasal prefix meaning 'your' - so literally 'your knowledge', meaning 'do you know?'. But they seem to all function in rather similar ways some tentative differentiations are glossed in the table.

There is room for debate about whether these are really tag-questions in a strictly grammatical sense. First, they may occur with sentences in non-declarative format, specifically with imperatives. Interrogatives and imperatives are mutually incompatible-it follows that Yélî Dnye tags are not themselves indicators of sentence type (see Sadock and Zwicky, 1985). Note however this is true of English tags too (cf. "Pass the salt, will you?"), so English and Yélî tags are very different in nature from, e.g. sentence final particles which replace markers of imperative or interrogative force in many SOV languages. Secondly, they can occur on sentences that are clearly about the speaker's domain of knowledge, and thus not candidate questions, as in the following:

<3> $y: i \quad$ wa $\quad$ nya nê, lama?

There FUT3.PUNCT get 3Punct.1sObject your.knowledge

'There they'll pick me up, you know?'

\footnotetext{
${ }^{3}$ These tags do not unambiguously indicate questions, however, as shown below.

${ }^{4}$ A sharp-eyed review noted that particle éé appears both before and after the clause, but in the former position it has a different expletive function.
} 


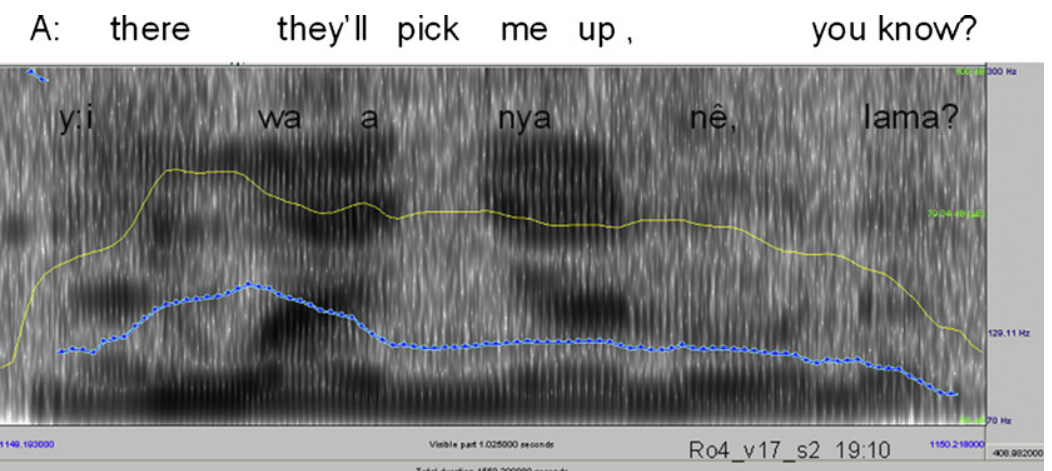

B: (nods)

Fig. 3. Intonational integration of a tag.

So here we have an assertion followed by a separate speech act, demanding acknowledgement of receipt of the assertion. Nevertheless, in this example the tag is seamlessly integrated in the overall falling contour of the clause, as shown in Fig. 3 above.

Thirdly, this distinction between a first and second action is often reflected in a gap between assertion (or other speech act) and the tag. Fourthly, the prior action may already have been responded to before the tag! In this case the tag seems to request an upgraded affirmation. For instance, in the following, $\mathrm{M}$ is giving instructions to $\mathrm{W}$ about arrangements for his feast, which are received with a nonverbal eye-brow flash and a nod, followed after a short pause by a sotto voce 'Alright'. M pursues this with a tag (falling intonation), presumably looking for more definitive uptake, but only gets an $\mathrm{mm}$.

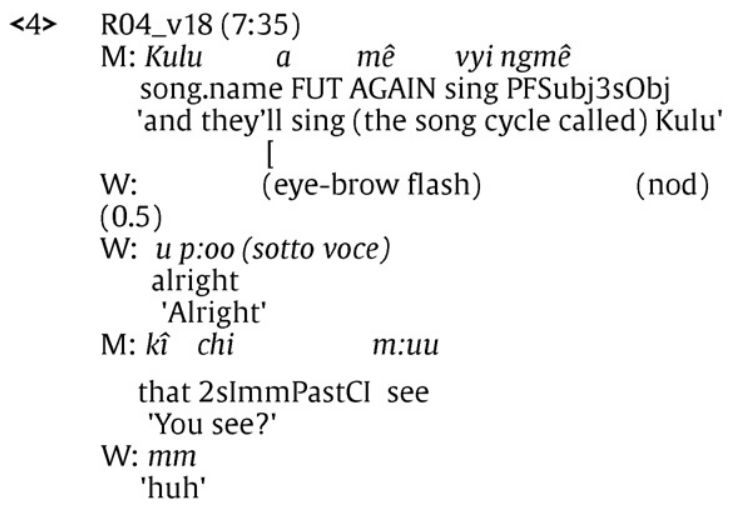

Finally, tags - especially apii and kwi, which are imperative in form - can also be addressed to another addressee than the declarative they follow, in which case they mean essentially 'please confirm this to the other guy'. In the following example, I instructs $\mathrm{M}$ in shell-money procedure, then turns to the respected elder $\mathrm{K}$ for endorsement of his instructions. This again makes the point that tags are at least potentially independent speech acts.

<5>R03_V19_s2

I to M: tp:ee mââ ngmê chi tpyé, kn:ââcha pyw:oo, child male INDEF 2sImmPastCI be.born base 2sImmPastCI+Deictic searching 'When you have a son, you search for the base kê (shell money) ngm:aa kn:ââ cha pyw:oo, security.for.shell base 2 sImmPastCI+Deictic searching you search for its deposit payment, mgêmîndapî mye cha pyw:oo. high.value.shell also 2 sImmPastCI+Deictic searching M: (nods) and for the marriage ndapî'

I to K: apii, Km:iinjênê?

'Right, Km:iinjênê (name of K)?' 
Table 2

Wh-words in Yélî Dnye, organized topically.

\begin{tabular}{|c|c|c|c|}
\hline Wh-word & Gloss & Structure & Remark \\
\hline n:uu & Who? & monomorphemic & $\begin{array}{l}\text { applies to any named thing } \\
\text { other than a place }\end{array}$ \\
\hline nanê & Who-ERGATIVE? & monomorphemic & intrinsically case marked \\
\hline lukwe & What? & monomorphemic & \\
\hline ló & Which? & monomorphemic & \\
\hline angê & Which? & monomorphemic & rare \\
\hline angênê & Where (static location only)? & angê+nê 'which?one' (not really analyzable) & \\
\hline anyi & Whither/Whence? & monomorphemic & \\
\hline ló $y: i$ & Whither/Whence? & ló $y: i$ 'which place.anaphoric' & \\
\hline angênté & How (method)? & angê+nté 'which+like' & \\
\hline \multirow[t]{2}{*}{ lónté } & How (is it)? Which method? & ló+nté 'which+like' & \\
\hline & Which kind of? & & \\
\hline yémi/yimi & How many? & monomorphemic & \\
\hline angêntoo & How big? & angê+ntoo 'which size' & \\
\hline lóntoo & How big? & ló+ntoo 'which size' & \\
\hline angêndy:ââ & How tall/long? & angêe+ndy:ââ 'which tall/long'? & \\
\hline anté & When & monomorphemic & \\
\hline angodo & When & dialect variant (P:uum) & \\
\hline ló dini ghi ngê & At what time segment? & ló+dini+gh+ngê which+time+part+ADV & \\
\hline lukwe(u) dîy:o & Why? & lukwe+dîy:o ‘What?reason' & \\
\hline
\end{tabular}

Table 3

Frequency of different Wh-word types.

\begin{tabular}{lcc}
\hline Type of $w h$-word by category & Frequency & Percent \\
\hline Thing (What?) & 49 & $40 \%$ \\
Place (Where?) & 28 & $23 \%$ \\
Person (Who?) & 15 & $12 \%$ \\
Manner (How?) & 12 & $10 \%$ \\
Reason (Why?) & 8 & $6 \%$ \\
Time (When?) & 6 & $5 \%$ \\
Amount (How much?) & 4 & $3 \%$ \\
Other & 1 & $1 \%$ \\
Totals & 123 & $100 \%$ \\
\hline
\end{tabular}

\subsection{Content or Wh-questions}

There are over a dozen core Wh-words in Yélî Dnye, as given in Table 2. The language is unusual in the number of (synchronically) monomorphemic question words. Unlike in many languages (Bhat, 1991), there is little overlap between such words and existential quantifiers; however ló 'Which', can function in this way (ló kópu 'some news', ló dini 'long ago').

A few notes are in order on special properties of this inventory. First, the 'who' morpheme ( $n: u u)$ can be used to question the identity of anything other than a place which has a proper name, for example a boat, or a tame pig (pigs get human names and are thus assimilated to the clan system $) .5$ Second, a distinction is made between the 'where' of places or static entities, and of directions of movement, but in the latter case there is no further distinction between 'whence' and 'whither', since the language specifies source-anchored vs. goal-anchored motion in the meaning of verbs (see Levinson, 2006).

In addition to those forms listed, questions words can be freely generated with Wh-adjective ló 'Which X', as in ló pini 'Which man/person?', ló tpile 'What things?', ló kópu dyuu? 'What bunch of things?'. Although it is possible to be more specific using these analytic forms (specifying, e.g. gender as in ló dmââdî? 'Which girl?'), in many cases it is not clear why a multi-morpheme phrase (like ló dini ghi ngê ‘At what time part, i.e. when?') is used in place of a monomorphemic expression.

In the sample of around 120 wh-questions from conversation analyzed here, these different Wh-word types were, naturally enough, not used with equal frequency. The following table gives the distribution, not of forms, but of functions grouping, e.g. lo pini? 'Which person?' and n:uu 'Who' together under 'person', and so forth for the other forms. The 'What thing?' forms are by far the most common, with place and person in second and third place. Low frequency clearly partially corresponds to the multimorphemic character of the lesser used wh-expressions (Table 3).

Let us now turn to the syntactic hosts for these Wh-phrases. Recollect from above that Yélî Dnye is a language with relatively free phrase order but strong SOV and verb-final tendencies. Like a number of such languages (Ultan, 1978), Yélî

\footnotetext{
${ }^{5}$ Why then gloss it as 'who?', asks a referee. Because boats and pigs are treated as honorary humans: only entities that can receive human like names can be so queried.
} 
Table 4

Position of the Wh-word in Wh-questions.

\begin{tabular}{|c|c|c|c|}
\hline & Initial phrase position & Second or subsequent phrase position & Total in all positions \\
\hline NTRI particles & $100 \%(21)$ & 0 & $15 \%(21)$ \\
\hline Wh-word alone & $100 \%(38)$ & 0 & $28 \%(38)$ \\
\hline Wh-word in clause & $44 \%(34)$ & $56 \%(43)$ & $57 \%(77)$ \\
\hline Total sample, all types & $68 \%(93)$ & $31 \%(43)$ & $100 \%(136)$ \\
\hline
\end{tabular}

Dnye does not require the question-word (bold in the examples below) to be fronted - it can occur "in situ" (in the locus normal for a constituent of that type, e.g. an adverbial):

<6> a. nkéli ngê kada anté wa a y:0o

boat ERG before when FUT CLOSE set.off.from

'When will the boat leave'

b. kêndapî ngópu yémi a tóó

shell.money your.possession how.much 3sPres.Cont sits

'How much shell-money have you got?'

In simplex clauses, however, it is often fronted for information-structure purposes.

$<7>\quad$ a. Ló nkéli k:oo Yidika a wowo

Which boat inside Yidika 3sFut embark

'Inside which boat did Yidika embark?'

b. n:uu ngê Osborne brothers $u$ kpêê dê kêna

who EXP Osborne brothers 3POSS experience Dual Abeleti

'To whom was there experience of the Osborne brothers at Abeleti (i.e. who knew them)?'

(Experiencer dative-subject)

From a sample of 136 wh-questions and 'next-turn repair initiators' (e.g. particles of the kind what?, eh? for requesting repair of the previous utterance) as given in Table 4, we can extract the following tendencies. ${ }^{6}$ We can see from the table that $43 \%$ of items are one word (or one phrase) questions or next-turn repair initiators, which are trivially in turn initial position. But $57 \%$ of wh-words occur in full verbal clauses, and of these the majority (56\%) do not occur in phrase-initial position.

Mostly these non-initial wh-words occur in second phrase position, with a topic or subject in initial position:

$<8>\quad$ Ka, mu pini ngê ló kópu ngma a

OK that man ERG which message INDEF.ABS DEIC.3Past

$d y: \hat{a} a ̂ n e \hat{e}$

send MonofocalSubj.3sgObj.RemPast

'OK, that man which message did he send?'

Occasionally when sentences have complete NPs (all major arguments are omissible), the Wh-phrase occurs further downstream as in the following example where it exceptionally occurs after the verb:

<9> Éé, 'N:aata tp:oo nmo ka nkîngî lukwe u dîy:o

Hey name 3POSS.son us CERT+3PresCI fearing what its reason

'Hey, the son of ' $\mathrm{N}$ :aata is fearing us for what reason?'

Many languages restrict the syntactic loci that can be questioned - restricting questioned elements to major arguments, or even just to subjects. In contrast, Yélî Dnye is catholic in what can be questioned - any adjunct, or item in a postpositional phrase can be questioned. If the wh-word is moved, however, all elements of the phrase must be moved together - there are for example no stranded prepositions as in English Who did John talk to?. Consequently wh-words can occur with all cases and all postpositions, as the following non-exhaustively illustrate:

\footnotetext{
${ }^{6}$ The next-turn repair initiating particles are included here for completeness - they can be thought of as querying a whole utterance, and may or may not take the form of Wh-words.
} 
$<10>$
a. $k \hat{\imath}$
kópu $u$
nt:uu lukwe?
Equative (Absolutive)
Dem.unmarked affair 3Poss reason what
'What caused this?'
b. ala nee nanê ndê ngê
Demon.Prox canoe who.ERG make.boat MFS3sORemPast
'Who made this canoe?'
c. n:uu ngmê chi vy:a Absolutive 0
who 3INDEF.ABS 2sImmPast hit
'Whom did you hit?
d. n:uu k:ii Alotau dêlee knî Comitative adjunct
who COMIT Alotau 3sImmPastPI go.fol 3Dual.Intrans
'With whom did he go to Alotau?'
$\begin{array}{llll}\text { e. n:uu } k a \quad \text { dêr:oo } & \text { Dative Goal }\end{array}$
who DAT/ABL 3ImmPastPI give.to.3
'Whom did he give it to?'

Long-distance movement of wh-phrases has been the subject of an enormous amount of linguistic theorizing. But for Yélî, movement out of a lower clause and into a matrix clause has only been found in elicited sentences, and such structures are clearly avoided. The following elicited example shows raising from a slot (marked with underline) in an embedded clause, which seems to be theoretically possible if hardly used.

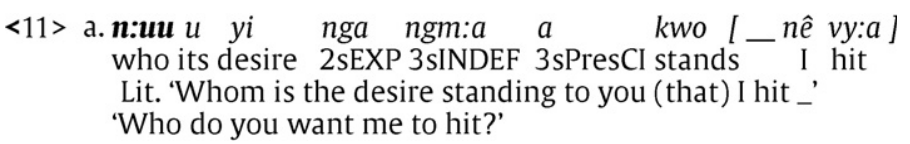

Finally, a few words about next-turn repair initiators (like English what?, which man? pardon?, huh?), which invite the original speaker of a trouble source to repeat or clarify what was said. In Yélî, where a specific problem is located, a wh-word is used to locate the trouble source (as in ló pini? ‘which man?', ló Mgââ? 'Which person called Mgââ?'). General requests for the repetition or repair of the whole utterance usually employ particles based on a long front or central vowel (:ee,:êê, occasionally éé), with or without nasality, often with special prosody.

\subsection{Alternative questions}

This is a minor type of question in Yélî Dnye space (2x)-there were just three occurrences in the corpus of questions (so constituting under $1 \%$ of the questions). They are formed just by conjoining two declaratives, or in the case of the data in hand, just two noun phrases, with ó 'or' (see example below). They will play no further role in this report.

$<12>\quad$ a. $\quad$ yéépî wédi ngomo ó kaa ngomo?
sago.thatch house or palm.fan house?
'Sago leaf house or fan-palm leaf house?' (for thatch)

\section{Questions and their functions}

For this study, questions were defined as all utterances that were either interrogative in form, or were in some large sense information seeking. Since in this language polar questions are not morphosyntactically marked, and not identifiable (as far as we can currently judge at least) by prosody, all polar questions excepting tag-questions are essentially defined by function. Moreover, analysis of the wh-questions also shows that except for 4 cases out of 123 , these question types were in a broad sense information seeking. All but those four of the utterances in the corpus, then, together with a few exceptional tagquestions, are seeking information - very few questions, for example, function as rhetorical questions (exceptions illustrated below).

But within this broad characterization of information seeking function, three major sub-functions can be distinguished:

seeking new information, either as a sequence-initiating action, or as a follow up on prior information; ${ }^{7}$ seeking confirmation of an already adumbrated set of facts, or of a plan, or of an agreement;

\footnotetext{
${ }^{7}$ A reviewer questions whether these two functions should be lumped together on the grounds they cross-linguistically tend to be very differently formatted. But actually the distinction proves hard to maintain in coding, and given the tendency in Yélî Dnye for NPs to be omitted, there's no clear format difference.
} 
Table 5

Actions associated with different question types.

\begin{tabular}{|c|c|c|c|c|}
\hline & Seeking new information & Seeking confirmation & Initiating repair & Other \\
\hline Polar questions & $47.5 \%(93)$ & $44 \%(86)$ & $6.6 \%(13)$ & $0.5 \%(1)$ \\
\hline Wh-questions & $58.5 \%(72)$ & $0 \%$ & $38 \%(47)$ & $3 \%(4)$ \\
\hline Total for all Q-types & $52 \%(165)$ & $27 \%(86)$ & $19 \%(60)$ & $2 \%(5)$ \\
\hline
\end{tabular}

Table 6

Polar questions and action types: tags vs. declarative questions.

\begin{tabular}{lccc}
\hline Polar question types & Seeking new information & Seeking confirmation & Initiating repair \\
\hline Tag-questions & $9 \%(6)$ & $90 \%(60)$ & \\
Declarative questions & $69 \%(87)$ & $20 \%(26)$ & $1 \%(1)$ \\
All polar questions & $47.5 \%(93)$ & $44 \%(86)$ & 0 \\
\hline
\end{tabular}

asking for repair of the other speaker's just prior utterance, either because it was not heard clearly, or its sense was unclear, or for other reasons.

The distribution of these three functions over all types of questions in the corpus are shown in Table 5, from which it can be seen that overall the first function is predominant. There is however a distinct distribution of the other two functions over polar vs. wh-questions. First, the initiation of repair is largely (78\%) done by wh-questions, with the caveat that this category included by coding convention dedicated repair initiators like English uh?. Less than 7\% (13) of polar questions were used in repair. Second, wh-questions were not used at all to seek confirmation - this makes sense of course, since polar questions seek a simple affirmation and are better suited for the job.

Of the 196 polar questions, 34\% (67) were tag-questions, and overwhelmingly (60 out of 67) these tags were used to do confirmation, and only a handful (6) were used to seek new information. Table 6 makes the point that, if we take away the tags which predominantly are used to seek confirmation, nearly $70 \%$ of the remaining polar questions, declarative in form, are seeking new information.

Since tags seek confirming responses, they may be associated with all manner of social actions. For example, in the following case, $\mathrm{I}$ is chastising $\mathrm{K}$ for having anger inappropriate for his elevated position:

$<13>$ R03_v19_s2

I: pye d:uu dpî nód:e, mââwe daa nód:e kîpini, (0.5) apii?

Impersonal.we NEG.DEIC. 1PLHabCI angry big.man NEG angry that man right?

'you should never be angry, a big man is not an angry person, right?'

$\mathrm{K}$ : (looking away, nods minimally)

I: kidi mê nód:e, nyi mââwe kî̀ pini

2sNegIMP.CI angry 2s big.man that man

'Don't be angry, you are a big man, mate!'

\section{$\mathrm{K}$ : mumdoo}

truly

'True'

Among the non-question functions of questions are, as mentioned, a few 'rhetorical questions', like the following tag-question addressed to the same old man who learnt from the prior generation of experts:

$<$ 14> R03_v19_s2

I: daa m:iituwó dpî yé ngópu, cha w:ee?

NEG day.before.yesterday 1dualPast put PFSubj3sO 2sImmPastCI.DEIC understand

'We2 didn't do this just the day before yesterday, you understand?'

K: ala ngwo dny:oo yó

right.now 2DualNearPastCI put.RemPast

'We2 didn't do it just now!'

Note how, despite the tag, no simple 'yes' response occurs, but instead a more complex partially repetitive, upgraded response is used to display understanding. 
Table 7

Frequencies of addressed questions.

\begin{tabular}{lll}
\hline Question types & Addressed & Non-addressed \\
\hline Polar question & $175(90 \%)$ & $20(10 \%)$ \\
Wh-question & $110(89 \%)$ & $13(11 \%)$ \\
Totals & $285(90 \%)$ & $33(10 \%)$ \\
\hline
\end{tabular}

Table 8

Frequencies of different types of response.

\begin{tabular}{lcc}
\hline Type of response & Frequency & Percent \\
\hline Answer & 226 & $72 \%$ \\
Non-answer response & 46 & $15 \%$ \\
No response (verbal or visual) & 40 & $13 \%$ \\
Totals & 312 & $100 \%$ \\
\hline
\end{tabular}

\section{Questions and their responses}

The interactional style on Rossel Island is distinctive. Interlocutors generally choose to sit or squat on the ground within touching distance of each other, perhaps with one or two onlookers standing around. Although such a huddle may contain four or more persons, interaction tends to be clearly dyadic, in the sense that speakers and listeners tend to gaze at each other, so clearly engaging a particular other for an exchange of turns (for a comparative detailed study of the gaze patterns in question sequences, see Rossano et al., 2009). It follows that most questions will be understood as clearly addressed at a particular interlocutor by gaze, if not as well by other features. Speaker gaze to addressee occurred in 235 (73\%) of 320 questions in this sample. ${ }^{8}$ Mutual gaze also makes possible the extensive use of visual signals on the face, mentioned already in section 2.1 above, and further pursued below.

Rossel islanders freely address each other by name or kinterm, but in fact in the questions corpus this occurred only rarely ( 7 instances of 287). It is often obvious who is being addressed also by the topic of the question - the information requested may lie obviously in a particular participant's realm of expertise (as in "What boat did you come on?"). For most of the questions in the corpus ( 287 out of 320 ), this could be ascertained, and in $73 \%$ ( 210 of 287 ) of cases, this alone would have sufficed to pick out an addressee. It is this fact, of course, that makes it possible to use declarative forms as polar questions without special intonation.

Nevertheless, unaddressed questions occur, like the following delivered as an 'outloud' (unaddressed wondering) gazing out from the interaction:

$<15>\quad$ R03_v19_s2

$$
\begin{aligned}
& \text { K: Daach:a anyi kêdê pwiyé } \\
& \text { man's.name where 3CERT.CI go } \\
& \text { 'Where did Daach:a go?' } \\
& \text { Other participants: (no response) }
\end{aligned}
$$

The following table gives the frequencies of clearly addressed vs. not clearly addressed questions taking all address features (gaze, address terms, proprietary information) into account: it shows that $90 \%$ of all questions seem clearly addressed to a particular addressee or addressees. Note that there is no greater tendency for polar questions to have clearer addressed status than for wh-questions, which one might have expected on the basis of the unmarked declarative form of polar questions being more dependent on clues to their interpretation (Table 7).

In the great majority of cases (95\%), the addressee who is selected by gaze, address form or subject matter is indeed the one that responds.

Turning to the responses themselves, the basic patterns are given in Table 8, where it can be seen that in three quarters of the cases questions get direct answers. Non-answer responses are various, and include reciprocal questions, while no response at all can be occasioned, e.g. by the speaker himself offering a follow-up question, or by another speaker breaking in, or simply by a parallel action by another speaker taking precedence over a response. In another sample more carefully coded

\footnotetext{
${ }^{8}$ In another sample, of strictly dyadic interaction, speaker gaze occurred in nearly $80 \%$ of 300 questions, and in $53 \%$ was maintained throughout the question (see Rossano et al., 2009). In that sample, recipients returned the gaze during $67 \%$ of questions, and just under $60 \%$ of all questions are delivered with mutual gaze (reciprocal eye-contact) at some point in the delivery.
} 
for gaze, we found that lack of gaze by the recipient is a good predictor of lack of response (Rossano et al., 2009), suggesting that a major reason for no response is disengagement or lack of attention.

That questions successfully elicit answers is in line with any number of basic observations about the cooperative nature of conversation (Grice, 1987) or the nature of adjacency pairs (Schegloff and Sacks, 1973) for which question-answer sequences are canonical. The prediction of course is that where no adequate answer is provided, the questioner may repeat the question - as in the following example:

$<16>\quad \mathrm{I}$ : lónté dpîmo a kópu.

which.way 2dualHabPI DEIC talk

'How did you talk about it?'

K: (nods)

I: lónté dpîmo danêmbum?

which.way 2dualHabPI converse

'How did you converse about it?'

We turn now to responses to polar questions, where the restricted range of expected responses makes generalizations easier. A prediction arising from both grammatical studies and work on English conversation is that in the case of polar questions, the answer projected by the bias of the question is the 'preferred' response. Preferred responses are unmarked in character, and more frequent. Yélî Dnye polar questions, without all the complexities of English polarity-marked tags and the consequent nuances of bias, tend overwhelmingly to get confirming responses ( $92 \%$ of 153 instances), formulated according to the truth-affirming rule explained above.

Despite the narrow range of expected responses to polar questions, there is in fact still quite a range of options in Yélî Dnye, as laid out in Table 9. Note that both verbal and visual conventional signals are here listed. As mentioned, a special property of social interaction on Rossel island is the close spacing of participants, and the prolonged gaze between speaker and addressee. This affords a variety of quite subtle conventional displays on the face, of which the most prominent is the eye-brow flash and the intentional blink, often accompanied by a small nod (see Fig. 2). These two facial displays are quite adequate stand-alone responses to polar questions, where they affirm, following the pattern explained earlier (where, e.g. affirming "You didn't come?" means "I didn't come").

Roughly half of all responses to questions are either constituted or accompanied by visual displays of this or similar kind. For a subsample of 282 responses, 39 or $14 \%$ of responses consisted only of such a visual signal, without any accompanying verbal content. This is cross-culturally unusual (indeed unique in the sample in this volume), and is made possible by the extensive repertoire of conventional nonverbal signals.

Visual signals are functionally differentiated from verbal ones, in the sense that an eye-brow flash, or a nod and a blink, have somewhat different ranges of use than verbal nyââ 'yes' or its attenuated verbal cousins. The visual signals are both broader, in that they seem able to substitute for $k a$ 'OK' (as, e.g. in a response to a request), and narrower in that they seem to carry a suggestion of the kind 'naturally, of course' (cf. English ya, yup, etc.), and thus to count as downplayed responses.

Sometimes indeed visual responses are treated as inadequate, and followed by a repeated question, as in the following where I is ascertaining whether some people have indeed snubbed the old and venerable big man K. I repeats the question but now in negative format. $\mathrm{K}$ simply repeats the empty hand gesture. Note in this case although the polarity of the question is reversed, the gesture remains the same because it is not the nonverbal equivalent of "no", but rather a demonstration of "nothing, no food".

Table 9

Response types to polar questions.

\begin{tabular}{|c|c|c|c|}
\hline Affirming particles & Rough Glosses & Disconfirming & Gloss \\
\hline $\begin{array}{l}\text { nyââ } \\
\text { ii } \\
\text { éé } \\
\text { mm } \\
\text { :êê } \\
\text { ndê kópu } \\
\text { [repetition, whole or partial] }\end{array}$ & $\begin{array}{l}\text { 'yes' } \\
\text { 'yes indeed!' } \\
\text { 'indeed' } \\
\text { 'mm' } \\
\text { ‘yuh' } \\
\text { 'true words/thing' }\end{array}$ & $\begin{array}{l}\text { kelêe } \\
\text { [repetition with negation added] }\end{array}$ & 'no' \\
\hline Affirming visual signals & & Negating visual signals & \\
\hline $\begin{array}{l}\text { eye-brow flash } \\
\text { blink } \\
\text { blink-nod } \\
\text { nod }\end{array}$ & $\begin{array}{l}\text { 'yup' } \\
\text { 'mm' } \\
\text { 'yeah' } \\
\text { 'mm' }\end{array}$ & $\begin{array}{l}\text { head shake } \\
\text { wrist-flick } \\
\text { one shoulder shrug }\end{array}$ & $\begin{array}{l}\text { 'no' } \\
\text { 'none, not the case' } \\
\text { 'I don't want it' }\end{array}$ \\
\hline
\end{tabular}


$<17>\quad$ R03_v19_s2

I: nté pee nga ngma a kê ngópu

food piece to.you INDEF 3Pres give.to.1st/2nd PFSubj3sO

'Did they give you any food?'

K: (empty hand gesture) (coughs for a couple of seconds)

$\mathrm{I}: n g a$ dêpê kê ngópu,

to.you NEG3RemPastPI give.to.1st/2nd PFSubj3sO

'They didn't give you any?'

K: (empty hand gesture)

One other contrastive pattern of response to yes-no questions has been noted by students of English conversation, namely the contrast between Yes and an affirmative repetition - as in A: Did you go? B: Yes (or other affirmative tokens like yeah) vs. I did (or I did go, I went, etc.). In English, repetition instead of Yes is thought to carry possible implications that the question itself is not quite appropriately formed (Raymond, 2003), and thus to be associated with an expansion of the sequence. It may in some cases suggest that the producer of the repetition had already alluded to the very fact now up for confirmation (Schegloff, 1996). In the responses to Yélî polar questions, 17\% consisted of a repetition without an agreement or disagreement token (including visual signals). No full study of these cases has been undertaken, but there are suggestions that repetition might perform some of the same functions as in English. For example, in the following extract, $Y$ has been telling K how some visiting biologists caught snakes and preserved them by plasticizing their bodies. Y has already stated that the preserved snakes won't decay, but will last five hundred years. At this point $\mathrm{K}$, with a shoulder shrug that indicates something like amazement, asks:

$<18>\quad$ R04_v1_s3

K: d:oo mye daa wa dono ngê pyódu

Then REPET NEG FUT bad ADVZ become

'It won't go bad again?'

Y: d:oo mye daa wa dono ngê pyódu

Then REPET NEG FUT bad ADVZ become

'It won't go bad again'

K: kidi mê k:omo danê

2sNegIMP.CI trick/joke

'Don't kid me again'

Y: nyââ

'Yes (it won't go bad)'

Y produces in response (second line above) an exact repetition with a closely matched prosodic contour. Note both the occurrence of the repetition in a context in which the answer is already clear, and the small sequence expansion that follows.

Similarly, in the extract below, W says that the organizers of the Kulu song fest are going to fix the date of the performance this very day, and M asks whether they have already done so (he's going to fix the date of his own songfest accordingly). W's answer is a (slightly abbreviated) repetition, implying perhaps that the fact that the date has not yet been fixed was already implied by his previous utterance (there's no sequence expansion in this case).

$<19>\quad$ R04_v18

W: Kul- awêde l:âmol:âmo ngmê yi n:ii kópu

Song.name today fixing PFSubj3sOProx anaph. proN thing

'Kulu-they are going to fix it's date today'

M: ngmênê doo ngê yé ngópu day

But NEG3ProxPastPI yet put PFSubj3sO day

'But they haven't yet fixed the day?'

$\mathrm{W}$ : doo ngê yé ngópu

NEG3ProxPastPI yet put PFSubj3sO

'They haven't yet fixed it'

Disconfirming responses to polar questions have some interest as the exceptional type of response. Given the small number (only 8\%) of disconfirming responses, only the following tentative observation can be made, namely that whether or 
not there is a preliminary 'no' token, repetition with added negation seems to be required (i.e. 'no' alone is not an adequate response), as the following examples illustrate.

$$
\begin{aligned}
& <11>\text { a. n:uu } u \text { yi nga ngm:a a kwo [ nê vy:a ] } \\
& \text { who its desire 2sEXP 3sINDEF 3sPresCI stands I hit } \\
& \text { Lit. 'Whom is the desire standing to you (that) I hit _, } \\
& \text { 'Who do you want me to hit?' }
\end{aligned}
$$

<20> R03_v2_s2 (00:13:08)

K: kî̀ tpóknî, kî teacher ngmidip:uu a m:ii, teacher mye nîmo

That fellow.PL that teacher one with 3PresCI move teacher also 1sPresQuote

'Guys, this teacher came for only one thing, as teacher, I'm saying he's a teacher'

(1.0)

apii?

'right?'

R: kêle, daa teacher $u$ dîy:o

No NEG teacher 3Poss reason

'No, he's not come to be a teacher'

<21> R03_v27_s3 (00:01:24)
A: kîdpodo nga doo that work to.you NEG3ImmPastPI diy: a wo apii?
'Aren't you tired of working, eh?'
B: daawa diy:a
NEG3FutPI tire
'I am not tired'

<22> R03v27s3_24(00:02:51)

A: k:ii nkéli k:oo wópu

here boat inside embark

'she hopped on a boat here?'

B: daa wowo

NEG3PresCI embarking

'she didn't hop on' (an account follows about why not)

\section{Conclusion}

Questions and their responses in Yélî Dnye have a number of special properties, as we have seen. Polar questions have neither morphosyntactic nor clear prosodic marking, requiring inference of illocutionary force from their content. Tags seem able to carry force of their own, independent of the utterance which they follow, but nevertheless can be fully incorporated in a single prosodic contour. Wh-questions show a slightly unusual inventory of forms, with n:uu 'who' extended to named entities other than humans, and a distinction between static 'where' and motion 'where', but without a corresponding distinction between ablative and dative notions. The answering system belongs to the truth-confirming type, and it is interesting that the visual signals of assent and dissent fit the same pattern. These visual signals are themselves perhaps the most unusual feature of the Yélî question-response system - in their exact conventionalization, their prolix deployment, and their ability to routinely stand alone.

Despite all these special features, Yélî Dnye nevertheless reflects many universal tendencies. Those tendencies include a separation of grammatical machinery for content questions and polar questions (in this case, by leaving polar questions unmarked), the possibility of fronting wh-words (or rather phrases), and no outlandish constraints on what arguments or adjuncts can be questioned. In addition, rules for use have a familiar ring, including all the detailed expectations about the differential valuation of different kinds of response - the preference for answers over nonanswers, confirmations over disconfirmations, and 'yes' tokens over repetitions, which appear to take on extra meanings.

\section{Appendix A. Transcript conventions}

The practical orthography used here follows Henderson (1995) and Levinson (forthcoming). The vowel diacritics indicate vowel quality with IPA equivalents as follows: î is/u/, ê is/९/, ó is/o/while o is/ว/, é is/e/while e is/ع/, a is/æ/and â is/a/, and i and $\mathrm{u}$ have the normal values. Phonemic length is indicated by doubling, nasalization by a preceding colon. There are no consonant clusters, all digraphs and trigraphs indicating coarticulations. Thus mb signifies a prenasalized bilabial stop, dm a nasally released post-alveolar stop ( $t$ signifies dental/alveolar, d post-alveolar or retroflex). Stops may also be simultaneously 
bilabially released as indicated in tp or kp, or less transparently, mg (IPA/pmkp/), making altogether 56 consonants. There are no tones.

It is hard to gloss Yélî Dnye in a systematic readable way, due to the fact that a single morpheme tends to be both manyways ambiguous and portmanteau over many grammatical categories, making the Leipzig Glossing Rules impractical. A single morph could have, e.g. the gloss '1stPerson Plural Future or ImmediatePast Punctual Aspect IndicativeMood. Counterfactual Conditional.Antecedent'. Thus I have used a reduced system of the kind '1PIFut/ImmPast.PI.CounterF.Ante', including the following conventions:

Person:

Number:

Person/number in free translation:

Subject

Object

ERG

ABS

EXP

DAT

ABL

COMIT

NEG

POSS

DEIC

INDEF

Aspect:

Aspect+Mood:

Mood

PreN

PostN

Cond'1

CounterF

Transitivity

$\varnothing$

N-

RemPast

ImmPast

NearPast

Prox

\section{FUT}

CLOSE

CERT

REPET

Fol

PART

ADVZ

\section{$1,2,3$}

s, d, pl; Sing, Dual, Pl

$\mathrm{MF}=$ monofocal (singular or 1 st person)

$\mathrm{PF}=$ polyfocal (2nd and 3rd persons dual and plural)

we 2 = we dual, you3 = you three or more, etc.

$\mathrm{S} ;$ Subj

O; Obj

Ergative case

Absolutive case

Experiencer case

Dative case

Ablative case

Comitative case

Negative

Possessive pronoun

Deictic element

Indefinite element

Punct $=$ Punctiliar, Cont $=$ Continuous

$\mathrm{PI}=$ Punctiliar Indicative, $\mathrm{CI}=$ Continuous Indicative

Indic = Indicative, Imp = Imperative, $\mathrm{Hab}=$ Habitual

Preverbal nucleus or inflectional proclitic

Postverbal nucleus or inflectional enclitic

Conditional marker in antecedent

Counterfactual marker in antecedent and consequent

Trans; Intrans; Transitive/Intransitive Verb TV/IV

Zero morph; especially pre- and post-verbal enclitics (note: this is only marked where pertinent to the discussion)

Homorganic nasal archiphoneme used to mark 2nd person possession - it assimilates to the succeeding stop position

Remote Past tense - day before yesterday or before Immediate Past tense - earlier today

Near Past tense - yesterday

Proximal tenses, the three closest to coding time (for the punctual aspect: future, immediate past, near past, for the continuous aspect: immediate future, present and immediate past)

Future

Deictic element

Epistemic certainty element

Event repetition

Followed form of verb root

Particle

Adverbializer 


\section{References}

Bhat, D.N., 1991. Indefiniteness and Indeterminacy. Mimeo.

Chisholm, William, Milic, N.T., Greppin, J.A.C. (Eds.), 1984. Interrogativity. A Colloquium on the Grammar, Typology and Pragmatics of Questions in 7 Languages. Benjamins, Amsterdam.

Dryer, Matthew S., 2008. Polar questions. In: Haspelmath, M., Dryer, M.S., Gil, D., Comrie, B. (Eds.), The World Atlas of Language Structures Online. Max Planck Digital Library, Munich. (chapter 116)http://wals.info/feature/116.

Geluykens, Ron, 1988. On the myth of rising intonation in polar questions. Journal of Pragmatics 12, 467-485.

Grice, Herbert Paul, 1987. Logic and Conversation. Cambridge University Press, Cambridge.

Henderson, James E., 1995. Phonology and Grammar of Yele: Papua New Guinea. Pacific Linguistics Series B-112, 1-110.

Jones, Bob Morris, 1999. The Welsh Answering System. Mouton de Gruyter, Berlin.

Labov, William, Fanshel, David, 1977. Therapeutic Discourse. Academic Press, New York.

Levinson, Stephen C., 2005. Living with Manny Schegloff's dangerous idea. Discourse Studies 7 (4-5), 431-453.

Levinson, Stephen C., 2006. The language of space in Yélî Dnye. In: Levinson, S., Wilkins, D. (Eds.), Grammars of Space. Cambridge University Press, pp. 157-204.

Levinson, Stephen C., 2007. Repair and the optimizing of person reference-perspectives from usage on Rossel Island. In: Enfield, N., Stivers, T. (Eds.), Person Reference in Interaction. Cambridge University Press, Cambridge, pp. 29-72.

Levinson, Stephen C., forthcoming. A grammar of Yélî Dnye.

Raymond, Geoffrey, 2003. Grammar and social action: yes/no interrogatives and the structure of responding. American Sociological Review 68 (6), 939-967.

Rossano, Federico, Brown, Penelope, Levinson, Stephen, 2009. Gaze, questioning and culture. In: Sidnell, J. (Ed.), Conversation Analysis: Comparative Perspectives. Cambridge University Press, Cambridge, pp. 187-249.

Sadock, Jerold, Zwicky, Arnold, 1985. Speech act distinctions in syntax. In: Shopen, T. (Ed.), Language Typology and Syntactic Description: Clause Structure. Cambridge University Press, Cambridge, pp. 155-196.

Schegloff, Emanuel, 1996. Confirming allusions. American Sociological Review 102 (1), 161-216.

Schegloff, Emanuel, Sacks, Harvey, 1973. Opening up closing. Semiotica VIII (4), 290-327.

Selting, Margret, 1994. Question intonation revisited. In: Dressler, W., Prinzhorn, M., Rennison, J.R. (Eds.), Proceedings of the 7th International Phonology Meeting Phonologica 1992. Rosenberg \& Sellier, Torino, pp. 243-256.

Stenström, Anna-Britta, 1984. Questions and Responses in English Conversation. Lund Studies in English, vol. 68. Liber Förlag, Malmö.

Ultan, Russell, 1978. Some general characteristics of interrogative systems. In: Greenberg, J. (Ed.), Universals of Human Language, vol. 4. Stanford University Press, Stanford, pp. 83-124.

Stephen Levinson is co-director of the Max Planck Institute for Psycholinguistics, Professor of Comparative Linguistics at Radboud University Nijmegen, and is a fellow of the British Academy and the Academia Europaea. He has written over 150 publications on language and cognition, including books Politeness (CUP), Pragmatics (CUP), Presumptive Meanings (MIT), Space in Language \& Cognition (CUP), and edited collections (with Wilkins) Grammars of Space (CUP), (with Bowerman) Language Acquisition and Conceptual development (CUP), (with Jaisson) Culture and Evolution (MIT), (with Enfield) Roots of Sociality (Berg). His current research focuses on cognitive foundations for communication, and relations between language and cognition. 